\title{
Call for Special Issue Papers: Breastfeeding and the Black/African American Experience: Cultural, Sociological, and Health Dimensions Through an Equity Lens
}

\author{
Deadline for Manuscript Submission: October 10, 2020
}

Guest Editor: Sahira Long, MD; George Washington University School of Medicine

\begin{abstract}
Breastfeeding Medicine Editor-in-Chief Arthur I. Eidelman, MD, and Guest Editor Sahira Long, MD, plan to publish a special issue dedicated to Breastfeeding and the Black/African American Experience.

In view of the continued racial disparities in breastfeeding rates and support systems, Breastfeeding Medicine will be publishing a special issue dedicated to this major public health problem.
\end{abstract}

Submit abstracts by New Date: September 15, 2020, for consideration to Guest Editor Sahira Long, MD (slong@ childrensnational.org)

Manuscript Submission Deadline: October 10, 2020

Issue Publication Date: February 2021 during Black History Month.

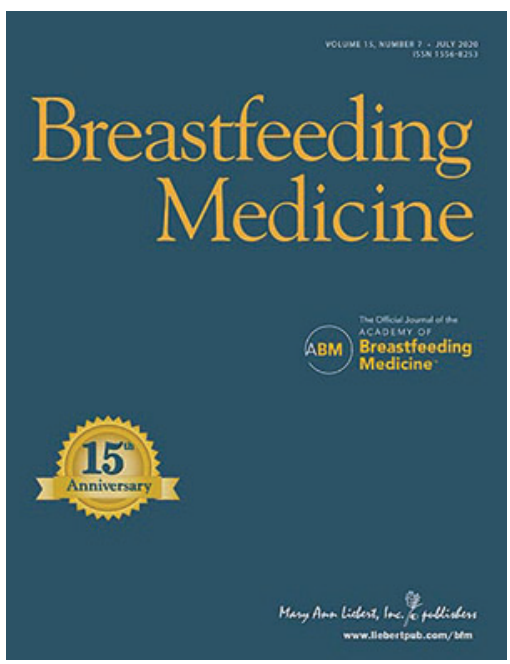

Benefits of publishing in Breastfeeding Medicine include:

- Fast and user-friendly electronic submission

- Rapid, high-quality peer review

- Maximum exposure: accessible in 170 countries

- Open Access options available

Visit Breastfeeding Medicine at www.liebertpub.com/bfm to learn more, read past issues, and view author submission guidelines.

\section{Visit the Instructions for Authors: www.liebertpub.com/bfm}

\section{Submit your paper for peer review online: https://mc.manuscriptcentral.com/bfm}

